\title{
O ECLIPSE, O DRAGÃO E O CINEMA ESTUDO SOBRE O FILME O ESTADO DO CÃO *
}

M ILTON José De ALmeidA**

Comecemos pelas informações aparentemente técnicas: este filme foi dirigido e produzido por Peter Brosens e D orjkhandyn Turmunkh, que também escreveram o roteiro. Peter Brosens nasceu na Bélgica, em 1962. Formado em geografia e antropologia, mudou-se para o Equador. Em 1993, na M ongólia, filmou o documentário City of the steppes, produzido por D orjkhandyn T urmunkh, que nasceu em U laanbaatar, M ongólia, em 1959. Formado em jornalismo, foi diretor de um programa bem popular na TV M ongol. Em 1992, escreveu, produziu e dirigiu 0 longa-metragem T ears of Lama.

O s cinegrafistas foram Sakhya Byamba e H eikki Farm, a trilha musical foi composta por C haro C alvo, o editor foi $\mathrm{O}$ ctavio I turbee teve mais quatro co-produtores: Lise Lense-M oller, Alok B. N andi, Kristiina Pervila, Jan Ewout Ruiter. E as empresas envolvidas foram Balthazar Film/Eurimages/Inti Films/Juniper Films/M agic $\mathrm{H}$ our Films/Point of View/Robch Toli.

Foi uma produção mongol-belga-dinamarquesa-finlandesa e holandesa, com N yam D agyrantz no papel do pastor, Baatar $G$ alsansukh, o poeta, Purevdavaa 0 yungerel, a contorcionista.

0 que acabamos de ler mostra esse ajuntamento industrial complexo, que acontecequando se produz um filme. E, de imediato, percebemos que não se pode analisar, eu diria interpretar, um filme como um texto escrito por um autor. Tampouco vêlo como obra coletiva, o que nos daria uma certa tranqüilidade conceitual.

\footnotetext{
* 0 estado do cão (State of dogs). Direção: Peter Brosens \& D orjkhandyn Turmunkh. N ohoi $O$ ron, 91 min. Bélgica/M ongólia, 1998. Cultfilmes, CF 0080, D istribuição: Flashstar H ome Vídeo, Barueri (SP).

* Laboratório de Estudos Audiovisuais O LH O, D epartamento de M etodologia de Ensino, Faculdade de Educação/U nicamp. E-mail: mja@directnet.com.br
} 
A produção de um filme é uma história de conflitos e negociações constantes que acontecem dia a dia, desde a escritura do roteiro, sua aprovação, alterações nesse roteiro quando da busca de financiamentos, a organização da produção, a contratação e ensaios dos atores, as locações e a filmagem propriamente dita, com os desafios técnico-estéticos da luminosidade, da película, dos enquadramentos, das interpretações e muito mais. G ravado em milhares de metros de película, que resultam em horas de imagens e sons, todo esse conjunto vai ser editado e ganhar um sentido cinematográfico, estético e político, comprimido em 90, 120 minutos. Ao final do processo, tornam-se produtos inquietantes: jornalísticos, documentais, querem nos fazer crer reais e verdadeiros os acontecimentos que sabemos serem somente fragmentos da realidade escolhidos politicamente; ficcionais querem nos fazer viver como reais e verdadeiras histórias e imagens que sabemos serem somente fragmentos da invenção.

U m comentarista, ${ }^{1}$ um pouco atrapal hado com as suas próprias classificações, escreve que 0 estado do cão é "um híbrido estranho, uma colcha de retalhos feita de documentário e ficção, filme de viagem e fábula animal, misticismo e realismo social". Com a expressão "híbrido estranho", ele resolveu a dificuldade, mas em diversas publicidades, nas quais a ambigüidade não pode aparecer, o filme é anunciado ora como documentário, ora como fábula, ora como ficção e até como filme surrealista.

O utro comentarista, francês, escreve: "Filme parábola, transita nesta zona de sombra onde se confundem ficção e documentário". ${ }^{2}$

Esses dois comentários mostram bem as dificuldades de se aplicar os tradicionais conceitos de gênero da classificação escolástica earistotélica a um produto da indústria cultural contemporânea que, apesar derealizar em técnica contemporânea a ideol ogia da objetividade visual da perspectiva renascentista, consegue ser ao mesmo tempo todos os gêneros e escapar dessetipo de enquadramento. Como se esse tipo de arte, a cinematográfica, tivesse conseguido homologar todos os gêneros artísticos, dramáticos e científicos ao mesmo tempo, subtraindo de cada um seu caráter distintivo, estabelecendo uma nova estrutura estética e política de equivalências, numa forma de arte transnacional de produção e reprodução do real. Arte política da transfiguração estética do real em imagens do real. ${ }^{3}$

D essa forma, o comentarista, ao falar de 0 estado do cão como "híbrido", revela o que acabamos de escrever. Esse filme é não só um híbrido de gêneros, mas um híbrido de ficção e realidade, emoção e 
educação política. Ao acrescentar "estranho", revela a inquietação que essa arte traz e que não está somente nesse filme, mas em todas as produções visuais atuais, queéo fato de serem todas ficções e colchas de retal hos, quer as que se apresentem como científicas, documentais, jornalísticas, como as declaradamente ficções. T odas "transitam nesta zona de sombra onde se confundem ficção e documentário". Ficção porque esse filme é uma edição singular de fragmentos de pessoas, animais e lugares reais captados na M ongólia e compostos em uma sequêencia narrativa que cria outra realidade em imagens, ao mesmo tempo em que documenta pessoas, animais elugares reais da M ongólia. E o inverso, lugares e pessoas reais deixam-se documentar pela arte cinematográfica que vai tran sformálos em seres de ficção e exibi-los em uma seqüência de imagens como se fossem ou tivessem sido reais. Simularão um outro real.

$M$ as exploremos mais essa zona de sombra.

Se a dedução lógica e coerente não fosse uma técnica capenga e prepotente de pensar, chegaríamos à conclusão de que todo filme é uma forma de captação e apropriação ocidental, capitalista, de imagens do real como matéria prima que, após serem transformadas pelas indústrias de entretenimento e informação, são devolvidas ao mercado como mercadoria estética e política, objetos do real feitos de arte e ideologia para serem consumidos como conhecimento, realidade, emoção. M as, a leitura atenta dos detal hes técnicos nos primeiros parágrafos revela uma indústria transnacional composta pelo conjunto de pessoas e órgãos de diferentes locais envolvidos no garimpo e exploração de imagens de pessoas e animais (personagens) e de paisagens (deserto e cidade) e percebemos que, apesar de arbitrariamente lógico, o quefoi dito acima tem sua parcela de verdade.

Prossigamos com o comentário de um espectador sueco: “ 0 filme é um dos melhores que eu vi. Algumas das cenas fazem você perder 0 fôlego. A história é sobre um cachorro que morre e seu espírito vaga para achar seu dono. M as a história não émuito importante aqui, pelo menos para mim não foi. É uma coleção de quadros da M ongólia. U ma boa quantidade de belas cenas com um toque surrealista. Acrescente algumas ótimas músicas e aí você tem o filme. Eu amei isso. M as não assista se você quiser algo com que se animar. Eles não escolheram exatamente os lugares mais agradáveis. Q uase tudo parece deteriorado e poluído". ${ }^{4}$

Q uais cenas teriam feito esse espectador sueco perder o fôlego, uma expressão que nos lembra a sensação de vertigem e descorporificação na descida de uma montanha russa? 0 s movimentos da câmera n'0 
estado do cão não são aqueles movimentos curvos, bruscos, espiralados, nem há aproximações e distanciamentos rápidos, fusões mirabolantes, secundados por música forte e envolvente, como nos filmes em moldes de cinema popular americano, em que os diretores parecem querer colocar o espectador sentado na câmera e sair correndo com ele, levá-lo até corpos ensangüentados, seguir balas de revólveres até as cabeças dos criminosos, fazêlo viajar sobre cidades...

V eja, por exemplo, a seqüência que se inicia no apartamento do profissional matador de cães. Em meio às suas ações cotidianas domésticas, ele prepara a arma, depois sai em busca dos cães. Enquanto percorre as ruas e terrenos da cidade, a câmera nos leva ora a seu lado, ora do lado de fora, ora perpendicular e presa ao chão nos oferece um grande olhar, ora se aproxima enos oferece um ol har um pouco oscilante deum detalhe. Barulhos da cidade, motores de automóveis e caminhões, latidos, sons secos de tiros evoz do narrador, todos esses sons alternam-se ou se mesclam como uma pequena peça musical, clássica e moderna ao mesmo tempo. Imagens e sons seguem seu curso comentando-se mutuamente sem tentarem governar o interior e a emoção do espectador.

D e modo geral e comercial, os filmes utilizam sons reais, sintetizados, e música paraimitarem, em imagens sonoras literais, convencionais, o drama visual. E os fazem coincidir com o ápice das sequêencias dramáticas. Esses sons e os chamados fundos musicais são, ao mesmo tempo, fundos emocionais e fundos políticos, quando conduzem e interpretam sempre da mesma maneira o drama que está sendo visto, seja um drama americano ou de qualquer parte do mundo, seja um drama de guerra, de assassinatos urbanos, de guerras estelares. D essa forma, guiado, confortável, amortecido ou educado por esse fundo sonoro convencional, o espectador globalizado dos filmes populares pode ver, com muita emoção, mas sem dor ou piedade, assassinatos, corpos estraçalhados, sangue. Como se esse espectador, numa espécie de vício cultural, procurasse ver sempre o mesmo filme... que o faz perder o fôlego.

Contrariamente, 0 estado do cão faz-nos respirar em seus muitos enquadramentos e planos quase ao nível do chão ou à altura de uma pessoa, em suas sequeências narrativas que se tornam "uma história real" através de ligações em cortes secos, ao mesmo tempo suaves, como se mordidos e ligados com saliva, em suas cenas que alternam distanciamento, aproximação, percepção, beleza e solidariedade emocional. Pede que 0 assistamos num estado de atenção poética, como faz o poeta, logo na abertura. D e costas para a câmera, que o vê de baixo em meio corpo, 
ele se vira para você e em poesia visual feita de olhar, gesto e palavra nos diz que precisa de "sete razões para viver", enquanto barulhos de pássaros e latidos de cães rimam ao fundo com a sua voz.

Sem descobrir porque o espectador sueco perdeu o fôlego, passemos ao comentário seguinte, em que ele diz que a história é sobre um cachorro que morre e seu espírito vaga para encontrar seu dono, mas que, para ele, essa história não é muito importante.

Se o filme é sobre um cachorro, seu espírito e seu dono, realmente a história tem pouca importância. Q uantos filmes e desenhos animados não há, cujos personagens são cachorros dotados de espírito e sentimentos humanos. Cada afirmação desse espectador sueco sobre o que ele considera a qualidade do filme é para mim um equívoco que desmerece o filme. Sinto-me na obrigação de mostrar que ele está certo na opinião geral e errado nos detal hes. Ele meirrita e me intriga, afinal de contas, tanto ele quanto eu gostamos muito e achamos maravilhoso o mesmo filme! I sso mostra o caráter cal eidoscópico dessa mercadoria chamada filme e o fato de um filme trazer tantas possibilidades de interpretação quantas são as pessoas que os vêem. Se todos vêem as mesmas imagens, porque todos as sentem e entendem de maneira diferente?

Emoção e inteligência fundem-se nas imagens em movimento no cinema. E as mesmas imagens vistas por todos ressoam no interior de cada espectador como diferentes, deixando-se interpretar pela sua visão histórica, estado emocional edisposições psíquicas, desejo, pela sua educação política evisual. O sfilmes são consumidos esteticamente por espectadores "nacionais", como uma espécie de mercadoria psicológica em que o "universal", a política do capitalismo e o cultural estão mesclados, fundidos, e são tanto economia quanto cultura..$^{5}$ São obras complexas, que escapam de simples explicações aparentemente lógicas e claras. Se há al guma lógica para a interpretação dos filmes, ela deve ser associativa, uma busca de significados dispersos em novas relações, uma excitação tanto para o intelecto como para a sensibilidade.

$M$ as deixemos em paz nosso espectador, numa noite nevada de inverno nórdico, na poltrona macia de um cinema sueco, bem aquecido, com as pernas confortavelmente cruzadas à frente, vendo Baasar recordar sua vida de cão pastor, como se fosse um documentário meio exótico. V ejamos 0 estado do cão como uma parábola, uma poesia, um conto.

0 terço final do filme é 0 centro da narrativa, o ponto de transformação ou o momento em que a história corre o risco de aniquilar-se.

N o começo, Baasar morre. 
Baasar viveu na M ongólia, onde os cães, animais positivos, quando morrem, reencarnam como homens e ele sabe que, ao morrer, antes que seu corpo se deteriore, deverá reencarnar como homem. M as como deverá reencarnar como homem, se foi morto por um homem? Como poderá reencarnar como homem, se foi cão pastor pertencente a uma digna família de pastores, degradou-se junto com ela ao virem para a cidade e, abandonado, tornou-se cão vira-lata? 0 filme transcorre no espaço-tempo do intervalo entre a morte e a reencarnação de Baasar. N esse tempo, misterioso e al egórico, Baasar recorda sua vida, tal vez para refletir se vale a pena reencarnar ou não nesse mundo injusto.

No zodíaco chinês antigo, o cão éo $11^{0}$ signo etem como características proteger o povo, prover alimento, espantar os demônios. E é um demônio que, afinal, vai resolver a dúvida de Baasar. O uvimos pela televisão que vai haver um eclipse do Sol. ${ }^{6}$ Televisões e jornalistas do mundo todo vêm para essa região da M ongólia, onde ele será melhor visível. O s repórteres nos dizem: "durante o evento, lamas rezarão e as pessoas baterão em objetos de metal para afugentar o dragão Rah. Acredita-se que R ah irá devorar o sol para provocar o fim do mundo, a menos que as pessoas consigam afugentar o mítico dragão". Ficamos sabendo que o eclipse é Rah, o dragão mítico que ameaça engolir o Sol. O s momentos anteriores ao eclipse são os momentos tensos da provável aparição de Rah. Segundo uma tradição popular chinesa, os dragões, durante $o$ inverno, vivem sob a terra, mas no segundo mês do ano vêm para a superfície e provocam o trovão e as primeiras chuvas.

Então, vem a chuva e há uma seqüência de planos quase abstratos de sons e água escorrendo por diversas superfícies, inundando a cidade, paralisando automóveis. Já antes tínhamos visto uma moça grávida em seu apartamento, depois no templo. Então, já poderíamos associar o seu filho ou filha que vai nascer a Baasar. 0 cão deve fazer coincidir sua reencarnação com o momento do parto e, assim, derrotar o dragão, se conseguir encarnar no ser que vai nascer da moça.

No extremo oriente, o dragão é considerado negativo e também positivo, pois produz o elixir da imortalidade. Em seusdiferentes aspectos, ele representa a essência básica yin-yang da cosmologia chinesa, na qual o sentido das coisas, da vida é produzido pela tensão e pelo movimento concomitante e constante desses dois componentes opostos. I soladamente, cada elemento tem pouca importância. Juntos, o dragão cinzaverde é o 0 riente, o Sol levante e a chuva da primavera, e o dragão branco, 00 cidenteea morte. ${ }^{7}$ Este é, então, o fundo fabuloso e tradicional que colore as cenas que estamos vendo nas seqüências finais do filme. 
Seqüências cujo ritmo visual se apressa pel o procedimento da montagem intercalada das histórias que ocorrem paralelas: o espírito vagante de Baasar na dúvida eà espera de reencarnar, o eclipse que se aproxima e as chuvas que acompanham a chegada do dragão, a moça grávida prestes a parir e a dançarina no campo de um templo.

Paremos um instante nessa dança de claro feitio hindu, na qual a dançarina parece ser tangida por um vento iogue sinuoso. Seus gestos curvos e delicados saem uns dos outros, como as energias do yin-yang. I magino perceber em sua dança-ritual uma certa concepção budista do conhecimento como tríplice corpo, uma tríade composta de dharmakaya, o ser verdadeiro; nirmanakaya, a formação histórica, representada por G autama Buddha e sambhogakaya, o efeito benéfico da comunidade.

Agora, voltemos às seqüências intercaladas: a cidade se inunda, a dançarina ritualiza gestos, o eclipse acontece, o sol desaparece, a cidade escurece. A moça grávida que havia voltado ao apartamento dormedurante o eclipse. Baasar consegue reencarnar. Será no filho da moça que vai parir. A dançarina ritualiza as forças da proteção da sociedade ameaçada por Rah. Ao mesmo tempo, ritualiza os movimentos do parto da moça. Baasar vence o dragão e reencarna, a moça dá à luz o filho.

A expressão dar à luz nos leva a lendas turco-mongóis, nas quais a luz, após ter visitado e fecundado uma mulher, sai dela na forma de um cão amarelo.

E imaginemoso tal do espectador sueco. A pós ter saído do cinema, vêmo-lo agora sentado à mesa de um restaurante aquecido. Com um copo de vinho nas mãos, ol ha pela vidraça a sua cidade bem arrumada sob a neve, a cidade que deu certo. I maginemos também o espectador mongol. Após ter saído do cinema, vemo-lo agora numa rua, andando por U laanbaatar, que você viu no filme, a cidade que não dá certo. Essa U laanbaatar que serviu de fundo geo-econômico para o filme. Sacos e plásticos que voam pelo mundo todo voam por lá também; apartamentos populares iguais aos que se vêem em toda periferia do terceiro mundo, feios e feitos para durar pouco, como o neocapitalismo quer seus trabaIhadores mundiais; templos em meio a lixo e coisas deterioradas; budismo tibetano e consumo.

T alvez agora, tendo visto pulsarem ao longo do filme as imagense os sons dos diversos fundos, possamos entender melhor aquele "híbrido estranho": barulhos e canções, tradição e história, len das e crenças, religião e economia, astronomia e deserto, emoção e política, convenção e poesia... como as palavras de Baalar Galsansukh, já ao fim do filme: 0 fim, 0 
começo... 0 bem, o mal... 0 preto, o branco... A primavera, o outono... A morte, a vida... 0 sol, a lua... A noite, o tempo... A comida, o deus... 0 futuro, o passado... 0 medo, o dragão... A força, a beleza... 0 homem, o cão... 0 céu, a terra... A alma, o destino... 0 presságio, o poeta... A memória.

U m filme é composto de fundos, muitos, todos transparentes. T odos estão à frente, mas cada espectador coloca um mais à frente, a seu modo, tempo e lugar.

\section{$\mathrm{N}$ otas}

1. D avid D algleish: www.subjective.freeservers.com/dogs.html

2. Philippe Simon, State of dogs - Les M étamorphoses du Chien: www.cinergie.be/ cinergie/ arch02/dogs.html

3. Pasolini, Pier Paolo, Empirismo eretico, M ilano: Garzanti EditoreSpa, 1991/Empirismo H ereje. Lisboa: Assírio e Alvim, 1982.

4. U ser Comments: Sweden, 3 N ov. 2000, Copyright (c) 1990-2001. The Internet M ovie $D$ atabase $L t d "$.

5. Jameson, Fredric, A cultura do dinheiro, Petrópolis: V ozes, 2001 e As marcas do visível, Rio: Graal, 1995.

6. Em 9 de março de 1997, um eclipse total do sol foi visível em al gumas áreas da M ongólia. J untamente com a limpidez do céu da M ongólia e o clima frio e seco, as condições excepcionais na angulação da sombra da lua e a baixa elevação do sol no horizonte $\left(23^{\circ}\right)$ fizeram deste fenômeno um acontecimento fantástico. 0 eclipse foi visível por volta das 8:50h (local) e durou cerca de 2 minutos e 24 segundos.

7. Biedermann, H ., Enciclopédia dei simboli, M ilano: Garzanti Editore, 1995. 